\title{
Grand Challenges in the Research of Fungal Interactions With Animals
}

\author{
Chengshu Wang ${ }^{1,2 *}$ \\ ${ }^{1}$ CAS Center for Excellence in Molecular Plant Sciences, Shanghai Institute of Plant Physiology and Ecology, Chinese \\ Academy of Sciences (CAS), Shanghai, China, ${ }^{2}$ CAS Center for Excellence in Biotic Interactions, University of Chinese \\ Academy of Sciences, Beijing, China
}

Keywords: host specificity, effector, immune evasion, antifungal immunity, chemical biology, community ecology

\section{OPEN ACCESS}

Edited and reviewed by: Gustavo Henrique Goldman, University of São Paulo, Brazil

*Correspondence: Chengshu Wang wangcs@sippe.ac.cn

Specialty section:

This article was submitted to Fungi-Animal Interactions, a section of the journal

Frontiers in Fungal Biology

Received: 02 September 2020 Accepted: 15 September 2020 Published: 30 October 2020

Citation:

Wang C (2020) Grand Challenges in the Research of Fungal Interactions With Animals.

Front. Fungal Biol. 1:602032. doi: 10.3389/ffunb.2020.602032
Different species of fungi and oomycetes play intimate pathogenic, symbiotic, physiological and ecological interactions with animals. Life threatening issues caused by fungi have been frequently reported not only to humans but also to other animals like amphibians and bats. For example, in addition to the invasive human diseases caused by the commensal fungi such as the species of Cryptococcus, Candida, Aspergillus, Coccidioides, and Pneumocystis genera, emerging threats have also been clinically reported from the infection of Fusarium and Mucormycetes fungi to the patients with a compromised immune system (Bongomin et al., 2017; Limon et al., 2017). The amphibian panzootic chytridiomycosis caused by the fungus Batrachochytrium dendrobatidis (Bd) has been causing the decline of about 500 amphibian species across continents over the past 50 years, a detrimental threat to ecosystem diversity and balance (Scheele et al., 2019). It is also ecologically problematic regarding the spread of the white-nose syndrome (WNS) disease caused by the psychrophilic fungus Pseudogymnoascus destructans (Pd) in bat populations (Puechmaille et al., 2011; Hoyt et al., 2020). It is technically challenging to investigate fungal infections in the populations of fish, shrimp and prawn which are frequently infected by fungi and Oomycetes, threatening the fishery and aquaculture industries to different levels (Gozlan et al., 2014). Otherwise, invertebrate pathogenic fungi have been well-investigated for their contributions to and functions in maintaining ecological balance and usages for biocontrol of agricultural pests (Li et al., 2015; Wang and Wang, 2017). Fundamentally, the conserved innate immune pathways, especially the antifungal Toll pathway, have been established by using the model organism Drosophila melanogaster as a genetically tractable system (Lemaitre et al., 1996; Ferrandon et al., 2007). However, overall, relative to the well-studied mechanisms (e.g., gene-forgene theory) of fungi-plant interactions (Yan and Talbot, 2016; Fernandez and Orth, 2018), the knowledge obtained for fungi-animal interactions is still fragmentary due to, if not all, the unilateral research focuses on either fungal pathology or host immunology. Many challenges still exist both mechanistically and technically in the research and understanding of the dynamic and diverse types of the defense/antidefense and temporal/spatial interactions between fungi and animals.

\section{CHALLENGES IN UNDERSTANDING THE MECHANISMS OF FUNGAL HOST-SPECIFICITY AND HOST-PREFERENCE}

Except for the saprophytic fungal species, fungi evolved into different pathotypes to infect either plants, metazoans, or other fungal species (i.e., the mycoparasites). Comparative genomic studies revealed that ascomycete insect pathogenic fungi are more closely related to plant pathogens than to mammalian pathogenic fungi (Shang et al., 2016). On top of this, individual fungal species evolved with a varied capacity to infect different ranges of hosts. Similar to the incomplete understanding of the origin of species, it is biologically interesting but mechanistically intriguing to understand the formation of fungal host-specificity even between the closely related fungal species. It has been recognized that host-pathogen interactions are one of the major driving forces leading to 
the diversification and (co-)speciation of both pathogens and hosts, which have resulted in the formation of the fungal species with different host ranges or strains with preference for different host species (Hu et al., 2014; Mei et al., 2020). For example, different species of the insect pathogenic Metarhizium fungi evolved with different host ranges of which the generalist species like M. brunneum, M. robertsii, M. anisopliae, and M. pingshaense can infect hundreds of insect species whereas the specialists such as $M$. acridum is acridid-specific and M. cicadae is found to only infect cicadas (Hu et al., 2014; Mongkolsamrit et al., 2020). The species of zombie-ant fungi Ophiocordyceps spp. even evolved to the level of one-fungus for one-ant species (Wichadakul et al., 2015; Araujo and Hughes, 2019). In addition, it has been found that different isolates of Beauveria bassiana demonstrated a varied degree of pathogenicity against the same insect species, the feature of isolate host preference (Mei et al., 2020). Similar characteristics have been found for the fieldcollected strains of the nematode trapping fungus Arthrobotrys oligospora against Caenorhabditis elegans (Yang et al., 2020). This kind of host specificity and host preference of insect/nematode pathogens is of important biological implications; however, the underlying mechanisms are still poorly understood (Kirzinger and Stavrinides, 2012). In addition to the metabolic associations (Xu et al., 2016; Tong et al., 2020), divergent G-protein coupled receptors (GPCRs) have been revealed in association with fungal host-specificity (Shang et al., 2020). However, the host ligand molecule(s) recognized by individual fungal GPCR remains elusive. In contrast to the concept of the non-host resistance (NR) raised for plant hosts (Ayliffe and Sorensen, 2019), animal NR responses have not been investigated. It is tempting to speculate if NR is present in animal hosts there will be a connection between it and fungal host specificity. Much effort is still required to tackle the challenges in understanding the secrets involved in fungal selection of animal hosts to infect, kill and digest for nutrients.

\section{CHALLENGES IN UNVEILING THE INNATE EFFECTOR MECHANISMS BETWEEN FUNGI AND ANIMAL INTERACTIONS}

Remarkable similarities have been demonstrated in the innate immune defense systems across plants, mammals and insects (Nurnberger et al., 2004; Leulier and Lemaitre, 2008). However, relative to the gene-for-gene theory established for the microbeplant interactions (Jones and Dangl, 2006; Jones et al., 2016), the concept of animal fungal effectors is still vague, and the innate effector mechanism has even been questioned for the interactions between fungi and animals since either the intimate apoplast structure is not present between fungal and animal cells (Lowe and Howlett, 2012; Cen et al., 2017), or the intracellular nucleotide binding-leucine-rich repeat immune receptors are largely missing in animals (Jones et al., 2016). During the studies of human and insect immunology, fungal pathogens have been largely treated as latent immunogenic factors, i.e., mainly the PAMP (pathogen-associated molecular pattern)triggered immunities (PTIs) (Ferrandon et al., 2007; Briard et al., 2019). For example, different non-entomopathogenic fungi such as A. fumigatus, A. nidulans, C. albicans, C. glabrata and
Fusarium fungi were used in the innate immunity studies of D. melanogaster by injection of live or dead fungal spores, which helped to establish the antifungal Toll pathway (Lemaitre et al., 1996; Ferrandon et al., 2007). Due to the common structure of fungal cell walls (Latgé et al., 2017), induction and activation of the Drosophila Toll pathway by non-pathogenic fungi are not surprising. In nature, however, entomopathogenic fungi infect and kill insects through the process of cuticle penetration and host hemocoel colonization along with cell wall structure remodeling, phenotype switch and inhibition of host immune defenses (Wang and Wang, 2017). Thus, caution has to be taken during the investigation of the interactions between fungi and animals.

Apart from PTIs, accumulated evidence has indicated that the innate effector mechanisms, i.e., the effector-trigged immunities (ETIs), are similarly present between microbe and animal interactions (Lopes Fischer et al., 2020). For example, the plant-pathogen effector-like proteins such as the small secreted cysteine-rich proteins (SSCPs) are similarly present in animal pathogenic fungi (Shang et al., 2016). Functional studies have revealed that the LysM effectors of the plant pathogenic fungi are also present in the entomopathogens such as B. bassiana with the chitin-binding activities to evade insect immunities (Cen et al., 2017). By using the Drosophila model, the serine protease PR1 of entomopathogenic fungi has been revealed as a "danger molecule," which can be detected by the host protease Persephone to boost the activation of the antifungal Toll pathway (Gottar et al., 2006; Issa et al., 2018). The metalloprotease of the M35 family of $M$. robertsii can directly cleave and inactivate the immune enzyme prophenoloxidases in insects to downregulate host immune defenses (Huang et al., 2020). Besides the cell wall PAMPs, a SSCP-like effector Sel1 of C. albicans could function as a PAMP molecule by interacting with the Toll-like receptors TLR2 and TLR4 to activate the NF-кB and MAPK (mitogen-activated protein kinase) pathways in mice (Wang et al., 2019). It has also been found that the small RNA encoded by $B$. bassiana could be deployed by the fungus to target and downregulate the expression of the Toll-pathway genes in mosquitos (Cui et al., 2019). Overall, the ETI mechanism of fungi-animal interactions is highly expected but limitedly understood what requires extensive research efforts by using different systems in the future.

\section{CHALLENGES IN REVEALING THE SMALL-MOLECULE-MEDIATED INTERACTIONS BETWEEN FUNGI AND ANIMALS}

Metabolomic studies have shown that differential accumulation of hundreds to thousands of metabolites could be detected from either fungi or animal hosts during fungi and animal interactions (Xu et al., 2015; Gonçalves et al., 2017; Kuo et al., 2020). Thus, in addition to the identification of effectorlike proteins, small molecules produced by fungi and animals may also be involved in cross-kingdom interactions. Indeed, different studies have revealed that small molecules, especially the secondary metabolites, are virulence factors of animal 
pathogenic fungi. For example, the virulence factor glitoxin produced by $A$. fumigatus can target host integrins to induce anoikis (a type of cell apoptosis) on lung epithelial cells (Haun et al., 2018). Deletion of the compound biosynthetic genes and insect bioassays revealed that production of the secondary metabolites is required for fungal virulence against insects such as the cyclopeptides destruxins produced by Metarhizium species (Wang et al., 2012), beauvericin (Xu et al., 2008), and beauverolide/beauveriolide (Yin et al., 2020) produced by $B$. bassiana as well as the immunosuppression drug cyclosporine produced by the facultative beetle pathogen Tolypocladium inflatum (Yang et al., 2018). The studies have shown that these molecules could directly or indirectly subvert host immune defense systems. Overall, chemical biology studies of animalpathogenic fungi may shed new light on the small-moleculemediated interactions between fungi and animals. However, there are both technical and scientific challenges in identifying the virulence-related metabolites (VRMs) produced by fungi and the VRM targeted protein/receptor(s) of animal hosts.

\section{CHALLENGES IN INVESTIGATING FUNGI-ANIMAL INTERACTIONS IN NATURE}

Animal mycosis occurs in different patterns in the fields like panzootic, epizootic and enzootic. The devastating panzootics of the bat WNS disease and amphibian chytridiomycosis are threating not only the safeties of the bat and frog populations but also the diversity and balance of different ecosystems. On the one hand, evolutionary, comparative and or population genomic studies have helped answer the regional origin, transmission, and pathogeography of the fungal pathogens (Puechmaille et al., 2011; Drees et al., 2017; O'hanlon et al., 2018; Scheele et al., 2019; Hoyt et al., 2020). On the other hand, however, very little is known regarding the factor(s) and mechanisms involved in determining the fate and consequence of the $\mathrm{Bd}$ and $\mathrm{Pd}$ infections of their hosts in nature. To meet these challenges, in addition to the urgent needs to set up the systems and models for laboratory mechanistic studies, fungal community ecology investigations of the $\mathrm{Bd}$ and Pd interactions with other microbes are necessarily required to help find if there is any practical way to block disease transmission and spread in host populations. Indeed, the studies have found that skin (co-habiting) microbiota on frogs could prevent morbidity and mortality caused by chytrid Bd (Harris et al., 2009; Mckenzie et al., 2012), and the bat cutaneous bacteria with antifungal activities had potential to protect bats from $\mathrm{Pd}$ infection (Grisnik et al., 2020).

Taken together with the pathogenic bacteria and viruses, invertebrate pathogenic fungi play important roles in maintaining host population density in different ecosystems (Wang and Wang, 2017). The ecology of invertebrate diseases has been studied for a long time, and has revealed the transmission, persistence, biotic/abiotic factor influence, and host densitydependent prevalence of invertebrate fungal pathogens (Hajek and Meyling, 2017). Depending on host population density, both epizootic and enzootic prevalence of fungal diseases can occur in invertebrate populations in the fields. Interestingly, co-epizootic of entomopathogenic fungi has also been found that different pathogens partitioned the habitat to attack the same insect host (Clifton et al., 2019). Different from the detrimental environmental threats caused by amphibian and bat pathogenic fungi, insect and nematode pathogens have long been used as environmentally friendly biocontrol agents (Wang and Feng, 2014). Thus, except for the similar requirement of the community ecology studies of invertebrate pathogens, environmental effects including biosafety of the biocontrol applications of entomopathogenic and nematophagous fungi require further investigations. A recent long-term monitoring and population genomic study of $B$. bassiana has revealed that the released strains to control pine caterpillars Dendrolimus punctatus could persist in the fields for a long time ( $>20$ years as being surveyed) but with low recovery rates and the ability to infect non-target insects, however, which demonstrated an enzootic pattern like local strains. In addition, in contrast to the arms-race model between pathogen and plant interactions (Moller and Stukenbrock, 2017), a trench-warfare scenario was suggested between the interactions of $B$. bassiana and insects in the field (Mei et al., 2020). Regarding the diverse fungi-animal interaction systems, more efforts are still required to meet the challenges in understanding the temporal and spatial interactions between fungi and animals in the fields.

\section{CONCLUSIONS}

Both animals and animal pathogenic fungi are taxonomically diverse, and different strategies have evolved from both sides to maximize their own adaptive fitnesses, survivals and reproductions. The obtained knowledge has helped us to understand the common or unique interactive mechanisms adopted by either side. However, extensive research efforts are still required by using different models and systems to facilitate the understanding of the nature of fungal host specificity, effector mechanism and chemical biology of molecular interactions, and temporal/spatial patterns of ecological interactions in the fields. In addition, it is also mysterious regarding the mechanisms involved in fungal control of host animal behaviors (Shang et al., 2015; Lovett et al., 2020), and host (especially the social insects) social immune responses against fungal infections (Roy et al., 2006; Konrad et al., 2012), which also raise challenges for future investigations.

\section{AUTHOR CONTRIBUTIONS}

The author confirms being the sole contributor of this work and has approved it for publication.

\section{FUNDING}

CW was funded by the Chinese Academy of Sciences (QYZDJ-SSW-SMC028).

\section{ACKNOWLEDGMENTS}

I would like to thank Gustavo Henrique Goldman and Stephanie Sadler for their comments and suggestions. 


\section{REFERENCES}

Araujo, J. P. M., and Hughes, D. P. (2019). Zombie-ant fungi emerged from non-manipulating, beetle-infecting ancestors. Curr. Biol. 29, 3735-3738.e3732. doi: $10.1016 /$ j.cub.2019.09.004

Ayliffe, M., and Sorensen, C. K. (2019). Plant nonhost resistance: paradigms and new environments. Curr. Opin. Plant Biol. 50, 104-113. doi: 10.1016/j.pbi.2019.03.011

Bongomin, F., Gago, S., Oladele, R. O., and Denning, D. W. (2017). Global and multi-national prevalence of fungal diseases-estimate precision. J. Fungi. 3:57. doi: $10.3390 /$ jof3040057

Briard, B., Karki, R., Malireddi, R. K. S., Bhattacharya, A., Place, D. E., Mavuluri, J., et al. (2019). Fungal ligands released by innate immune effectors promote inflammasome activation during Aspergillus fumigatus infection. Nat. Microbiol. 4, 316-327. doi: 10.1038/s41564-018-0298-0

Cen, K., Li, B., Lu, Y. Z., Zhang, S. W., and Wang, C. S. (2017). Divergent LysM effectors contribute to the virulence of Beauveria bassiana by evasion of insect immune defenses. PLoS Pathog. 13:e1006604. doi: 10.1371/journal.ppat.1006604

Clifton, E. H., Castrillo, L. A., Gryganskyi, A., and Hajek, A. E. (2019). A pair of native fungal pathogens drives decline of a new invasive herbivore. Proc. Natl. Acad. Sci. U.S.A. 116, 9178-9180. doi: 10.1073/pnas.1903579116

Cui, C., Wang, Y., Liu, J., Zhao, J., Sun, P., and Wang, S. (2019). A fungal pathogen deploys a small silencing RNA that attenuates mosquito immunity and facilitates infection. Nat. Commun. 10:298. doi: 10.1038/s41467-019-12323-1

Drees, K. P., Lorch, J. M., Puechmaille, S. J., Parise, K. L., Wibbelt, G., Hoyt, J. R., et al. (2017). Phylogenetics of a fungal invasion: origins and widespread dispersal of white-nose syndrome. mBio 8, e01941-17. doi: 10.1128/mBio.01941-17

Fernandez, J., and Orth, K. (2018). Rise of a cereal killer: the biology of Magnaporthe oryzae biotrophic growth. Trends Microbiol. 26, 582-597. doi: 10.1016/j.tim.2017.12.007

Ferrandon, D., Imler, J. L., Hetru, C., and Hoffmann, J. A. (2007). The Drosophila systemic immune response: sensing and signalling during bacterial and fungal infections. Nat. Rev. Immunol. 7, 862-874. doi: 10.1038/nri2194

Gonçalves, S. M., Lagrou, K., Duarte-Oliveira, C., Maertens, J. A., Cunha, C., and Carvalho, A. (2017). The microbiome-metabolome crosstalk in the pathogenesis of respiratory fungal diseases. Virulence 8, 673-684. doi: 10.1080/21505594.2016.1257458

Gottar, M., Gobert, V., Matskevich, A., Reichhart, J., Wang, C., Butt, T., et al. (2006). Dual detection of fungal infections in Drosophila via recognition of glucans and sensing of virulence factors. Cell 127, 1425-1437. doi: 10.1016/j.cell.2006.10.046

Gozlan, R. E., Marshall, W. L., Lilje, O., Jessop, C. N., Gleason, F. H., and Andreou, D. (2014). Current ecological understanding of fungal-like pathogens of fish: what lies beneath? Front. Microbiol. 5:62. doi: 10.3389/fmicb.2014.00062

Grisnik, M., Bowers, O., Moore, A. J., Jones, B. F., Campbell, J. R., and Walker, D. M. (2020). The cutaneous microbiota of bats has in vitro antifungal activity against the white nose pathogen. FEMS Microbiol. Ecol. 96:fiz193. doi: $10.1093 /$ femsec/fiz193

Hajek, A. E., and Meyling, N. V. (2017). "Fungi," in Ecology of Invertebrate Diseases, ed. A. E. Hajek and D. Shapiro-Ilan. (Hoboken, NJ: Wiley), 327-377. doi: 10.1002/9781119256106.ch9

Harris, R. N., Brucker, R. M., Walke, J. B., Becker, M. H., Schwantes, C. R., Flaherty, D. C., et al. (2009). Skin microbes on frogs prevent morbidity and mortality caused by a lethal skin fungus. ISME J. 3, 818-824. doi: 10.1038/ismej.2009.27

Haun, F., Neumann, S., Peintner, L., Wieland, K., Habicht, J., Schwan, C., et al. (2018). Identification of a novel anoikis signalling pathway using the fungal virulence factor gliotoxin. Nat. Commun. 9:3524. doi: 10.1038/s41467-018-05850-w

Hoyt, J. R., Langwig, K. E., Sun, K., Parise, K. L., Li, A., Wang, Y., et al. (2020). Environmental reservoir dynamics predict global infection patterns and population impacts for the fungal disease white-nose syndrome. Proc. Natl. Acad. Sci. U.S.A. 117, 7255-7262. doi: 10.1073/pnas.1914794117

Hu, X., Xiao, G., Zheng, P., Shang, Y., Su, Y., Zhang, X., et al. (2014). Trajectory and genomic determinants of fungal-pathogen speciation and host adaptation. Proc. Natl. Acad. Sci. U.S.A. 111, 16796-16801. doi: 10.1073/pnas.1412662111
Huang, A., Lu, M., Ling, E., Li, P., and Wang, C. S. (2020). A M35 family metalloprotease is required for fungal virulence against insects by inactivating host prophenoloxidases and beyond. Virulence 11, 222-237. doi: 10.1080/21505594.2020.1731126

Issa, N., Guillaumot, N., Lauret, E., Matt, N., Schaeffer-Reiss, C., Van Dorsselaer, A., et al. (2018). The circulating protease persephone is an immune sensor for microbial proteolytic activities upstream of the Drosophila toll pathway. Mol. Cell. 69, 539-550.e536. doi: 10.1016/j.molcel.2018.01.029

Jones, J. D., and Dangl, J. L. (2006). The plant immune system. Nature 444, 323-329. doi: 10.1038/nature 05286

Jones, J. D., Vance, R. E., and Dangl, J. L. (2016). Intracellular innate immune surveillance devices in plants and animals. Science 354:aaf6395. doi: $10.1126 /$ science.aaf6395

Kirzinger, M. W., and Stavrinides, J. (2012). Host specificity determinants as a genetic continuum. Trends Microbiol. 20, 88-93. doi: 10.1016/j.tim.2011.11.006

Konrad, M., Vyleta, M. L., Theis, F. J., Stock, M., Tragust, S., Klatt, M., et al. (2012). Social transfer of pathogenic fungus promotes active immunisation in ant colonies. PLoS Biol. 10:e1001300. doi: 10.1371/journal.pbio.1001300

Kuo, T. H., Yang, C. T., Chang, H. Y., Hsueh, Y. P., and Hsu, C. C. (2020). Nematode-trapping fungi produce diverse metabolites during predator-prey interaction. Metabolites 10:117. doi: 10.3390/metabo10030117

Latgé, J.-P., Beauvais, A., and Chamilos, G. (2017). The cell wall of the human fungal pathogen Aspergillus fumigatus: biosynthesis, organization, immune response, and virulence. Annu. Rev. Microbiol. 71, 99-116. doi: 10.1146/annurev-micro-030117-020406

Lemaitre, B., Nicolas, E., Michaut, L., Reichhart, J. M., and Hoffmann, J. A. (1996). The dorsoventral regulatory gene cassette spatzle/Toll/cactus controls the potent antifungal response in Drosophila adults. Cell 86, 973-983. doi: 10.1016/S0092-8674(00)80172-5

Leulier, F., and Lemaitre, B. (2008). Toll-like receptors-taking an evolutionary approach. Nat. Rev. Genet. 9, 165-178. doi: 10.1038/nrg2303

Li, J., Zou, C., Xu, J., Ji, X., Niu, X., Yang, J., et al. (2015). Molecular mechanisms of nematode-nematophagous microbe interactions: basis for biological control of plant-parasitic nematodes. Annu. Rev. Phytopathol. 53, 67-95. doi: 10.1146/annurev-phyto-080614-120336

Limon, J. J., Skalski, J. H., and Underhill, D. M. (2017). Commensal fungi in health and disease. Cell Host Microbe 22, 156-165. doi: 10.1016/j.chom.2017.07.002

Lopes Fischer, N., Naseer, N., Shin, S., and Brodsky, I. E. (2020). Effectortriggered immunity and pathogen sensing in metazoans. Nat. Microbiol. 5, 14-26. doi: 10.1038/s41564-019-0623-2

Lovett, B., Macias, A., Stajich, J. E., Cooley, J., Eilenberg, J., De Fine Licht, H. H., et al. (2020). Behavioral betrayal: how select fungal parasites enlist living insects to do their bidding. PLoS Pathog. 16:e1008598. doi: 10.1371/journal.ppat.1008598

Lowe, R. G., and Howlett, B. J. (2012). Indifferent, affectionate, or deceitful: lifestyles and secretomes of fungi. PLoS Pathog. 8:e1002515. doi: 10.1371/journal.ppat.1002515

Mckenzie, V. J., Bowers, R. M., Fierer, N., Knight, R., and Lauber, C. L. (2012). Cohabiting amphibian species harbor unique skin bacterial communities in wild populations. ISME J. 6, 588-596. doi: 10.1038/ismej.2011.129

Mei, L. J., Chen, M., Shang, Y., Tang, G., Tao, Y., Zeng, L., et al. (2020). Population genomics and evolution of a fungal pathogen after releasing exotic strains to control insect pests for 20 years. ISME J. 14, 1422-1434. doi: 10.1038/s41396-020-0620-8

Moller, M., and Stukenbrock, E. H. (2017). Evolution and genome architecture in fungal plant pathogens. Nat. Rev. Microbiol. 15, 756-771. doi: $10.1038 /$ nrmicro.2017.76

Mongkolsamrit, S., Khonsanit, A., Thanakitpipattana, D., Tasanathai, K., Noisripoom, W., Lamlertthon, S., et al. (2020). Revisiting Metarhizium and the description of new species from Thailand. Stud. Mycol. 95, 171-251. doi: 10.1016/j.simyco.2020.04.001

Nurnberger, T., Brunner, F., Kemmerling, B., and Piater, L. (2004). Innate immunity in plants and animals: striking similarities and obvious differences. Immunol. Rev. 198, 249-266. doi: 10.1111/j.0105-2896.2004.0119.x

O'hanlon, S. J., Rieux, A., Farrer, R. A., Rosa, G. M., Waldman, B., Bataille, A., et al. (2018). Recent Asian origin of chytrid fungi causing global amphibian declines. Science 360, 621-627. doi: 10.1126/science.aar 1965 
Puechmaille, S. J., Frick, W. F., Kunz, T. H., Racey, P. A., Voigt, C. C., Wibbelt, G., et al. (2011). White-nose syndrome: is this emerging disease a threat to European bats? Trends Ecol. Evol. 26, 570-576. doi: 10.1016/j.tree.2011. 06.013

Roy, H. E., Steinkraus, D. C., Eilenberg, J., Hajek, A. E., and Pell, J. K. (2006). Bizarre interactions and endgames: entomopathogenic fungi and their arthropod hosts. Annu. Rev. Entomol. 51, 331-357. doi: 10.1146/annurev.ento.51.110104.150941

Scheele, B. C., Pasmans, F., Skerratt, L. F., Berger, L., Martel, A., Beukema, W., et al. (2019). Amphibian fungal panzootic causes catastrophic and ongoing loss of biodiversity. Science 363, 1459-1463. doi: 10.1126/science.aav0379

Shang, J. M., Shang, Y. F., Tang, G. R., and Wang, C. S. (2020). Identification of a key G-protein coupled receptor in mediating appressorium formation and fungal virulence against insects. Sci. China Life Sci. doi: 10.1007/s11427-020-1763-1

Shang, Y., Feng, P., and Wang, C. (2015). Fungi that infect insects: altering host behavior and beyond. PLoS Pathog. 11:e1005037. doi: 10.1371/journal.ppat.1005037

Shang, Y. F., Xiao, G. H., Zheng, P., Cen, K., Zhan, S., and Wang, C. S. (2016). Divergent and convergent evolution of fungal pathogenicity. Genome Biol. Evol. 8, 1374-1387. doi: 10.1093/gbe/evw082

Tong, X. W., Wang, Y. D., Yang, P. C., Wang, C. S., and Kang, L. (2020). Tryptamine accumulation caused by deletion of MrMao-1 in Metarhizium genome significantly enhances insecticidal virulence. PLoS Genet. 16:e1008675. doi: 10.1371/journal.pgen.1008675

Wang, B., Kang, Q., Lu, Y., Bai, L., and Wang, C. (2012). Unveiling the biosynthetic puzzle of destruxins in Metarhizium species. Proc. Natl. Acad. Sci. U.S.A. 109, 1287-1292. doi: 10.1073/pnas.1115983109

Wang, C. S., and Feng, M. G. (2014). Advances in fundamental and applied studies in China of fungal biocontrol agents for use against arthropod pests. Biol. Control 68, 129-135. doi: 10.1016/j.biocontrol.2013. 06.017

Wang, C. S., and Wang, S. B. (2017). Insect pathogenic fungi: genomics, molecular interactions, and genetic improvements. Annu. Rev. Entomol. 62, 73-90. doi: 10.1146/annurev-ento-031616-035509

Wang, W., Deng, Z., Wu, H., Zhao, Q., Li, T., Zhu, W., et al. (2019). A small secreted protein triggers a TLR2/4-dependent inflammatory response during invasive Candida albicans infection. Nat. Commun. 10:1015. doi: $10.1038 /$ s41467-019-08950-3
Wichadakul, D., Kobmoo, N., Ingsriswang, S., Tangphatsornruang, S., Chantasingh, D., Luangsa-Ard, J. J., et al. (2015). Insights from the genome of Ophiocordyceps polyrhachis-furcata to pathogenicity and host specificity in insect fungi. BMC Genomics 16:881. doi: 10.1186/s12864-015-2101-4

Xu, Y., Orozco, R., Wijeratne, E. M., Gunatilaka, A. A., Stock, S. P., and Molnar, I. (2008). Biosynthesis of the cyclooligomer depsipeptide beauvericin, a virulence factor of the entomopathogenic fungus Beauveria bassiana. Chem. Biol. 15, 898-907. doi: 10.1016/j.chembiol.2008.07.011

Xu, Y.-J., Luo, F., Gao, Q., Shang, Y., and Wang, C. (2015). Metabolomics reveals insect metabolic responses associated with fungal infection. Anal. Bioanal. Chem. 407, 4815-4821. doi: 10.1007/s00216-015-8648-8

Xu, Y.-J., Luo, F., Li, B., Shang, Y., and Wang, C. (2016). Metabolic conservation and diversification of Metarhizium species correlate with fungal hostspecificity. Front. Microbiol. 7:2020. doi: 10.3389/fmicb.2016.02020

Yan, X., and Talbot, N. J. (2016). Investigating the cell biology of plant infection by the rice blast fungus Magnaporthe oryzae. Curr. Opin. Microbiol. 34, 147-153. doi: 10.1016/j.mib.2016.10.001

Yang, C. T., Vidal-Diez De Ulzurrun, G., Gonçalves, A. P., Lin, H. C., Chang, C. W., Huang, T. Y., et al. (2020). Natural diversity in the predatory behavior facilitates the establishment of a robust model strain for nematode-trapping fungi. Proc. Natl. Acad. Sci. U.S.A. 117, 6762-6770. doi: 10.1073/pnas.1919726117

Yang, X., Feng, P., Yin, Y., Bushley, K., Spatafora, J. W., and Wang, C. (2018). Cyclosporine biosynthesis in Tolypocladium inflatum benefits fungal adaptation to the environment. mBio 9, e01211-e01218. doi: $10.1128 / \mathrm{mBio} .01211-18$

Yin, Y., Chen, B., Song, S. X., Li, B., Yang, X. Q., and Wang, C. S. (2020). Production of diverse beauveriolide analogs in closely related fungi: a rare case of fungal chemodiversity. mSphere 5, e00667-e00620. doi: 10.1128/mSphere.00667-20

Conflict of Interest: The author declares that the research was conducted in the absence of any commercial or financial relationships that could be construed as a potential conflict of interest.

Copyright (c) 2020 Wang. This is an open-access article distributed under the terms of the Creative Commons Attribution License (CC BY). The use, distribution or reproduction in other forums is permitted, provided the original author(s) and the copyright owner(s) are credited and that the original publication in this journal is cited, in accordance with accepted academic practice. No use, distribution or reproduction is permitted which does not comply with these terms. 